\title{
The Application of Reflectance Transformation Imaging (RTI) in Historical Archaeology
}

\author{
Harold Mytum (1D) J. R. Peterson
}

Accepted: 25 April 2018 / Published online: 17 May 2018

(C) The Author(s) 2018

\begin{abstract}
Reflectance Transformation Imaging (RTI) is a technique for the production of images in the lab or field that allows for the recording and analysis of artifacts so that their surfaces can be investigated more fully than with traditional visual inspection or photography. Using standard photographic equipment and freely available software, images can be generated for recording, analysis, publication, public interpretation, and conservation purposes. This report results from innovative trials of the technique and reveals its potential for widespread application within historical archaeology for investigating many artifact categories including clay pipes, molded glass, gravestones, and bone and copper alloy artifacts.
\end{abstract}

Abstracto La Formación de Imágenes por Transformación de Reflectancia (RTI por sus siglas en inglés) es una técnica para la producción de imágenes en el laboratorio o el campo que permite la grabación y el análisis de artefactos para poder investigar sus superficies, más completamente, que con la inspección visual o la fotografía tradicional. Utilizando un equipo fotográfico

\footnotetext{
H. Mytum $(\bowtie)$

Department of Archaeology, Classics and Egyptology, University of Liverpool, 12-14 Abercromby Square, Liverpool L69 7WZ, UK

e-mail: hmytum@liv.ac.uk

J. R. Peterson

School of Histories, Languages and Cultures, University of Liverpool, 12-14 Abercromby Square, Liverpool L69 7WZ, UK
}

estándar y un software de libre disponibilidad, se pueden generar imágenes para fines de grabación, análisis, publicación, interpretación pública y de conservación. Este informe es el resultado de pruebas innovadoras de esta técnica y revela su potencial para su aplicación generalizada dentro de la arqueología histórica para investigar muchas categorías de artefactos, incluso tubos de arcilla, vidrio moldeado, lápidas, artefactos de hueso y de aleaciones de cobre.

Résumé L'imagerie par transformation de la réflectance (ITR) est une technique de production d'images en laboratoire ou sur le terrain permettant d'enregistrer et d'analyser des artefacts de façon à ce que leur surface puisse être étudiée plus précisément que par l'inspection visuelle traditionnelle ou la photographie. À l'aide d'équipement photographique standard et de logiciels usuels, il est possible de générer des images à des fins d'enregistrement, d'analyse, de publication, d'interprétation publique et de conservation. Le présent rapport est tiré d'essais novateurs de la technique. Il révèle la possibilité de l'utiliser largement dans le domaine de l'archéologie historique pour l'examen de nombreuses catégories d'artefacts, notamment les pipes en argile, le verre moulé, les pierres tombales et les artefacts en alliage d'os et de cuivre.

Keywords photography $\cdot$ artifacts $\cdot$ Reflectance Transformation Imaging 


\section{Introduction}

One of the major concerns in historical archaeologywhether in the field or lab-is the visual recording of artifacts. Traditional photography, often with the application of natural or artificial oblique light, can often produce excellent results (Rivera 2014). However, in some cases the nature of the artifact surface, or its coloring, makes such images less than desirable. Some alternative methods have been applied including photogrammetry (Selden 2015), laser scanning, and threedimensional (3-D) scanning (Means et al. 2013). The use of Reflectance Transformation Imaging (RTI) can provide an alternative form of documentation, and also an analytical tool to enhance investigation of designs and texts on artifacts, to examine technology and production methods, and to examine the state of the artifact with regard to conservation. The images are two-dimensional (2-D), but recent developments in processing allow what has been termed $21 / 2-\mathrm{D}$ because of the qualities of the image produced (Duffy 2013:3). This technical brief outlines the scientific basis of the method, but mainly concentrates on the practical process of applying this low-cost method of recording, based on experience gained in a variety of field and lab situations in a variety of countries. Examples will be taken from gravestone recording and artifact studies including clay pipes, glass, bone, and copper alloy. The method has also been applied for conservation purposes in both the field (Gabov and Bevan 2011) and the laboratory (Padfield et al. 2005; Earl et al. 2010), and recent innovations have adapted it to underwater use where it can allow image creation even in turbid water conditions where normal photography is ineffective (Selmo et al. 2017).

\section{Scientific Basis of RTI}

RTI uses many images of the same artifact taken from the same location, each with light from a known direction, to create a composite image. The computing is based on polynomial texture mapping (PTM), first developed by Tom Malzbender (Malzbender et al. 2001) and subsequently enhanced by others including Cultural Heritage Imaging (CHI 2018). A program has been developed that combines the data from all the separate images into one file. This can then be viewed in a variety of ways.
The basic principle of RTI is that light reflects off the surface of an object, and the program can identify the light that reflects at right angles to that surface, the surface normal. By calculating the surface normal for numerous points, the topography of the surface is defined. This therefore creates a virtual 3-D topography of the object surface, which can allow the simulation of raking light from any direction, or the modeling of a more evenly lit composite image.

\section{Principles and Practices of RTI and H-RTI}

The production of images in the lab can be through either the standard RTI or the highlight RTI (H-RTI) method. Standard RTI can be achieved through the use of a dome, which consists of a light-proof structure with a large number of bulbs, each of which can be turned on individually to provide sufficient illumination to allow the fixed digital camera suspended over the artifact to take an image. By taking a sequence of images using all the lights, the data required for processing is acquired. The dome used in the Ancient Documentary Artifact (RTISAD) project at the Universities of Oxford and Southampton is a plastic hemisphere $1 \mathrm{~m}$ in diameter, which comprises four sections for easy transport between different museum and archive locations. The dome contains 76 LED lights, with the camera placed outside the top of the dome on an external metal frame (Earl et al. 2010; Piquette 2011). The lights are located so that as each one is illuminated it is at different positions around each circle at $15^{\circ}, 40^{\circ}$, and $65^{\circ}$, with others adjacent to the camera and therefore close to $90^{\circ}$ (Fig. 1). The camera lens points down through an aperture directly onto the object immediately below, with the target spheres to one side but within shot. This system is thought to be appropriate for objects up to $17 \mathrm{~cm}^{2}$ in area (Piquette 2011:17), but the rule of thumb is for the light source to be a consistent distance away from the artifact, with this being four times the diameter or diagonal measurement for larger objects.

The investment in the construction of a dome would only be worthwhile for a project with large numbers of artifacts to record, but would then be cost-effective because of the saving of staff time and the uniformity and comparability of the results between different objects, as all the final images would have been created under an identical set of conditions. Pawlowicz (2015) has developed a smaller portable dome, 12 in. in 
a

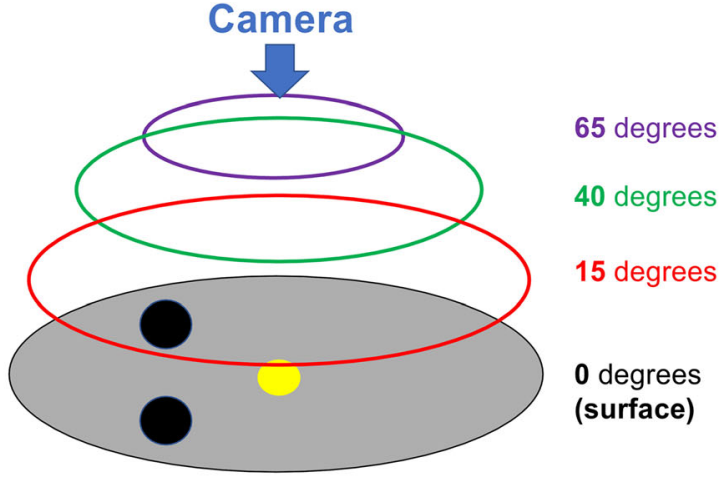

b

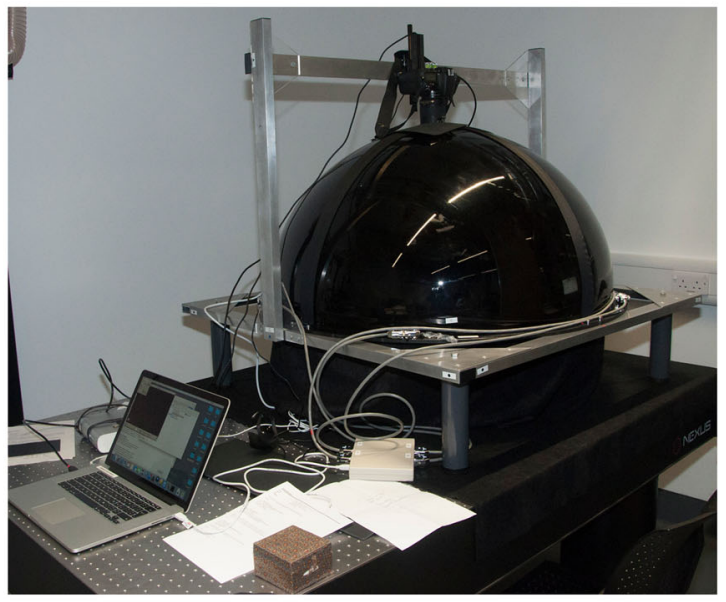

C

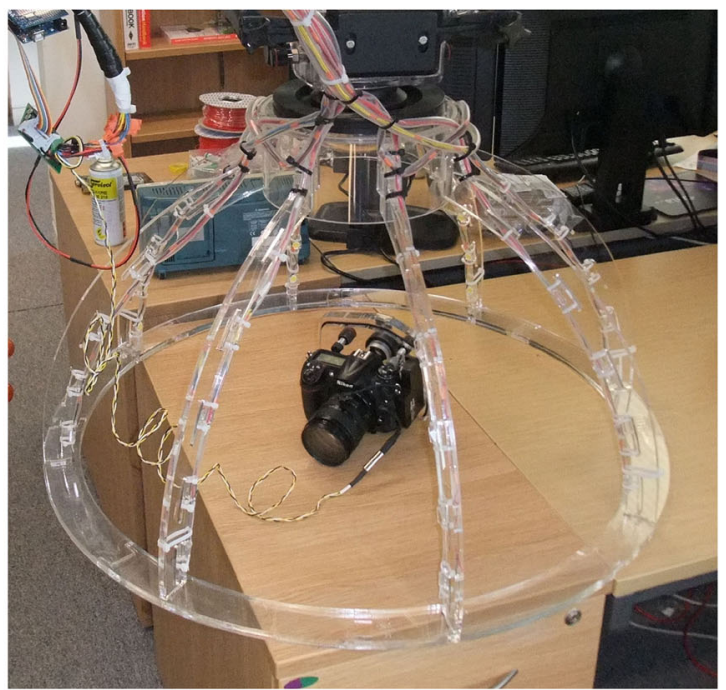

Fig. 1 RTI domes: (a) structure of the dome- - lights are arranged around the dome providing a variety of angles onto the artifact (yellow disc) with target spheres (black) to one side (image by Harold Mytum, 2017); (b) RTI dome produced by Kirk Martinez, University of Southampton, installed at the British Museum (photo by Kirk Martinez, 2014); (c) prototype fixed-lighting semisubmersible RTI photography dome designed and built by David Selmo at University of Southampton (photo by David Selmo, 2013). diameter and with 48 lights, which is battery powered or uses a wall transformer, and can be used to create images of artifacts in situ or in a field lab; a portable larger dome is in development. Experiments with a robot arm have been conducted, but a dome has been preferred (Duffy 2013:12). Recent experiments have also developed a portable dome for use in underwater archaeology (Selmo et al. 2017).

The H-RTI method avoids the need for a dome. This more flexible approach can be carried out in the laboratory, but is particularly effective in the field (Fig. 2). It is slower than with a dome, but it is easy to use in the field, and has also now been implemented successfully in underwater contexts. The equipment required is extremely portable and flexible, involving few items beyond those already expected in a field photographic kit; how this may be achieved, and what may be acceptable variations when out in the field, are discussed below.

\section{Equipment Required for H-RTI}

The digital camera must have the facility to take RAW images, manual settings for aperture and exposure, and be able to operate manually with flash. It should be set with ISO at 100-200, shutter speed no slower than 1/60 (and ideally more) and with an aperture of $\mathrm{f} / 5.6-\mathrm{f} / 11$, with RAW images of at least $8 \mathrm{MB}$. It is important to consider the effects of depth of field in creating the most powerful images. Full details of how to set up the camera are provided by Duffy (2013).

A normal lens is preferred; autofocus can be used during initial setting up, but must be returned to manual before the photographs are taken. Wide-angle lenses may be necessary, but Duffy (2013:5) suggests that lens calibration will be required to avoid the creation of a distorted image.

Other equipment required for H-RTI includes the following items and specifications.

- A neutral density filter is necessary to remove the ambient light when images are being taken during the day. If the photographs are to be taken at night, this may not be required.

- The flash gun requires a wireless link to the camera to synchronize flash and shutter release. This allows the flash to be held some distance from the camera, and also removes cables, which often appear in images. 
Fig. 2 H-RTI in the field: $(a)$ terrestrial application on an Irish gravestone using string to ensure the flash is a consistent distance from the target; the string is then moved out of the way and the camera shutter is remotely triggered; note the target spheres either side of the base of the headstone (photo by Terry Collins, 2015); (b) underwater application at $26 \mathrm{~m}$ depth on a ship timber in the western Mediterranean (photo by Gustau Vivir, 2013).
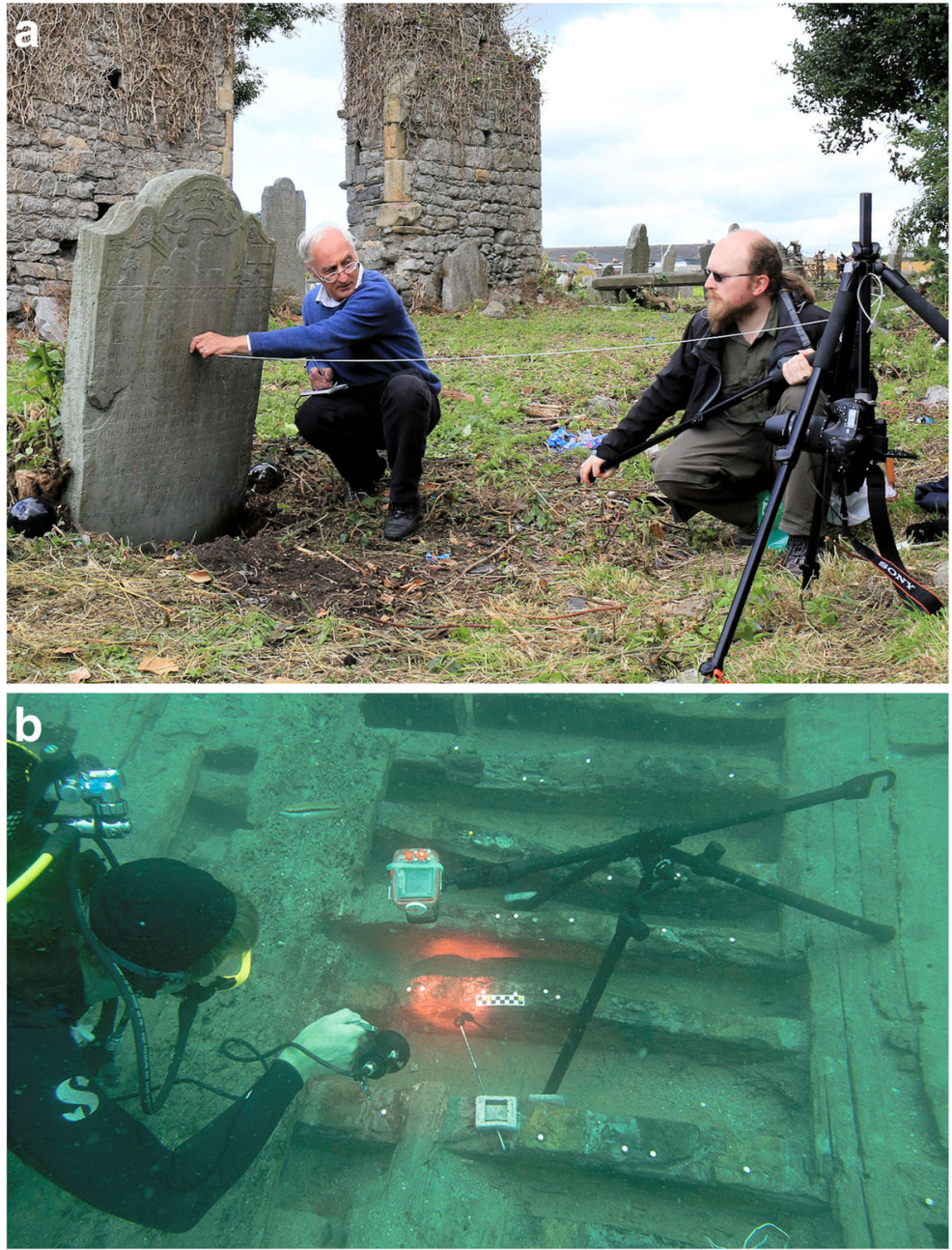

- A substantial tripod that will remain completely still while the entire sequence of photographs is taken should be used, and weights may be required to secure it in windy conditions. For vertical surfaces a tripod can be used to position the camera facing the artifact. It may be possible to use a tripod to photograph horizontal surfaces or artifacts in situ in the field, but care has to be taken to avoid shadows from the legs; in the laboratory a camera stand is very effective.

- Reflective target spheres in a range of sizes (two of each), together with material such as "Blu Tack" to fix these objects onto a surface, are necessary. The spheres should be either black or red so that the reflected highlight can be recognized by the software. Mounting spheres on wire rods can allow them to be firmly fixed into the ground. We have found that spherical glass beads and Christmas tree decorations can be effective target spheres.

- A laptop (Windows or Mac) to download and process data in the field, and to check that the quality is sufficiently high, is useful. It is also better if the camera is connected to a laptop during the taking of the images, as these are easier to check with the larger screen, and this avoids disturbing the camera to view its screen to ensure the images are suitable.

- Recording forms with standard information for the archive to accompany the images with details of the camera settings, distance of the camera from the object, and any notes regarding conditions should be used.

- Color check target, $18 \%$ greyscale card, and scale are useful in one or more preliminary photographs. These then allow any postprocessing to achieve 
color balancing and also the creation of scaled images. These can be combined with any information board with details of the object and its context on the first image for a particular artifact, allowing easy separation of the images relating to one subject from those of another. This image is not used in the later stages of processing.

- A supply of measuring tapes, string, tape, and cable ties will ensure that any ad hoc arrangement of equipment can be achieved with minimum interference of the light source and ensure the stability of the camera.

- Dark, preferably black, background of fabric or card for photographing small artifacts is useful. In the field, objects such as gravestones can be photographed without a background, but the depth of field needs to be limited to ensure the memorial surface is in focus but the surroundings are not.

- A step ladder up which the holder of the flash can climb to achieve the required distance and angle for the images when recording large artifacts, or where the feature to be recorded is raised, is helpful. The flash may need to be a considerable distance from the object, and this is particularly challenging logistically for those above the artifact. It may be possible to use an extendable pole to which the flash can be attached, but care must be taken so that the flash points in the appropriate direction onto the target. Photographing at night can remove all ambient light.

- If the floor on which the tripod will be placed may vibrate (e.g., historical house floorboards), it may be useful to have a sheet of stout plywood that will minimize impact of individual floorboard movement affecting the tripod feet. Likewise, soft sand or very damp ground can cause movement during the time taken to capture all the necessary images. Movement near the tripod should be minimized once it is set in position and in focus.

\section{Software Required for RTI and H-RTI}

The same software is used whichever method has been used to collect the images. Regularly check to see if updated and expanded versions of the software have become available for either processing or viewing the data. The terminology is explained by Duffy (2013) and CHI (2013, 2014). The required software is as follows:
- $\quad$ RTIBuilder, RTIViewer User Guide \& HSH Fitter (CHI, Inc.): <http://culturalheritageimaging. org/What_We_Offer/Downloads/>. Accessed 27 July 2017.

- PTM Fitter (HP Labs): <http://www.hpl.hp. com/research/ptm/downloads/download.html $>$. Accessed 27 July 2017.

- Java 6: <http://www.java.com/en/>. Accessed 27 July 2017.

- Adobe updates/plug-in downloads: <www.adobe. com/support>. Accessed 27 July 2017.

\section{The H-RTI Method in Practice}

The RTI software requires the exact position of the light source for each image, and this would be difficult to calculate with handheld positions of the flash. By positioning two fixed reflective target spheres within the image frame, each image has points of light on the spheres, which allows the software to calculate the direction from which the light source came. This means that manual operation, with as many handheld positions as it is feasible to provide, can be used as the basis for creating the composite images in H-RTI. These should be at angles from $15^{\circ}$ to at least $75^{\circ}$ above the surface being recorded, and from as many directions as possible in the other dimension. The early processing stages require the target spheres, but later the image set can be trimmed so that the outputs do not include them (Fig. 3).

The H-RTI method allows for the application of RTI even in relatively restricted locations and for larger objects. Duffy (2013:4) considers that $2 \mathrm{~m}$ is the largest dimension, and that much larger than this may be problematic because of the difficulties in creating suitably strong oblique lighting from a sufficient number of angles. With larger objects, it is difficult to obtain even lighting over the whole object from the flash, but this limitation excludes few items of material culture in historical archaeology. Duffy (2013:6) suggests that the light source should ideally be four times the diameter of the artifact away from the subject, but we have found that gravestones can be reasonably recorded at as low as two times the largest dimension when limitations in positioning the flash or to ensure sufficient light from the flash have prevented setting up the camera at a greater distance. Large surfaces that have extensive graffiti or sculptural carving (Cosentino et al. 2015) 
Fig. 3 Taking and processing the images: (a) artifact with target sphere; (b) artifact image trimmed; (c) blended image of light sources for one image. (Images by authors, 2017).
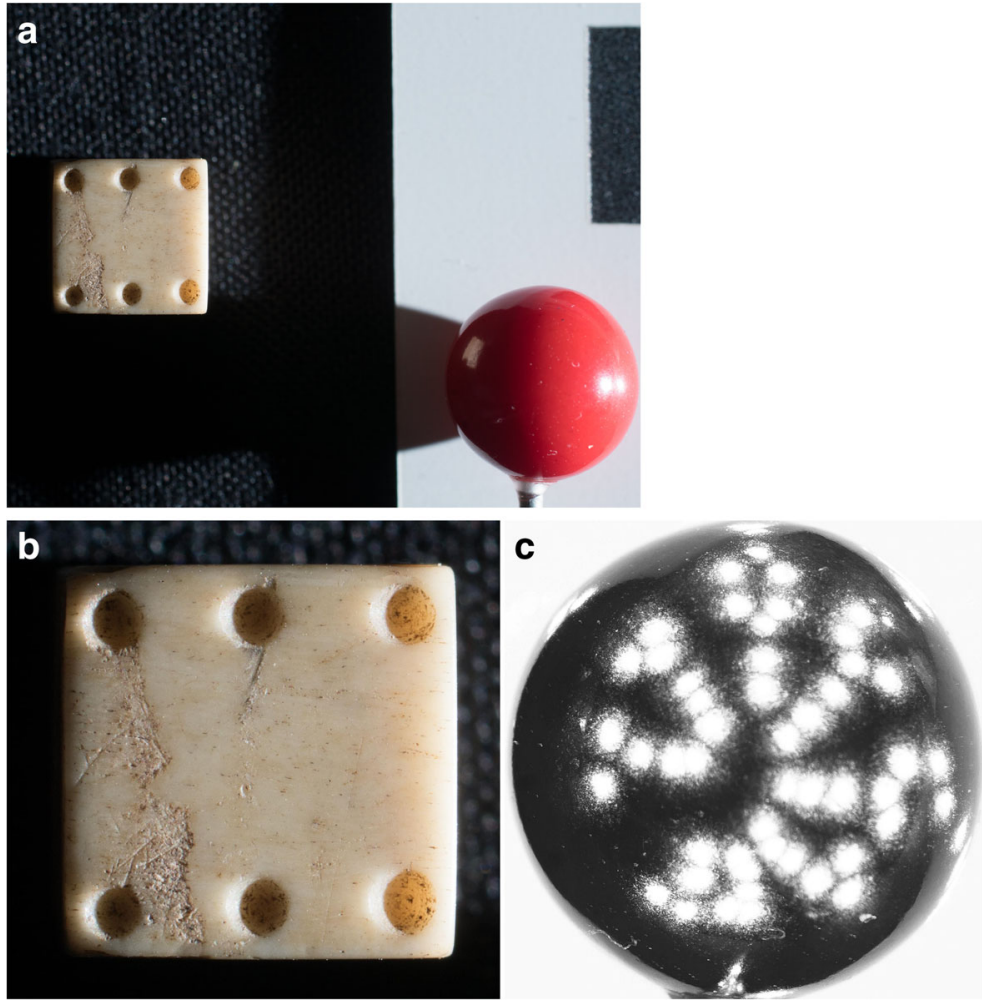

can be split into several segments for recording and analysis. Each segment is then processed, but the output images from each segment saved as JPEG or TIFF files can then be merged using standard software to create composite images covering the whole surface.

\section{Processing RTI Data}

The data require a number of stages of processing; only a summary is provided here as more detail is given by Duffy (2013). The processing can be time-consuming, so it may be effective to have one team member devoted to dealing with the data from one field session while the field team is working on the next. This also allows for feedback should any problems such as camera movement be noted in the processing. RAW images are first checked for quality, and any unsuitable images can be discarded (such as those with an assistant or shadow in view), with the remainder converted into DNG files using, for example, Adobe Photoshop; batch editing including orientation of the images may be required. The images are then saved as JPEGs, with a naming system that identifies the artifact — without spaces - in the file name. The JPEG size affects the resolution of the final images. It is at this point that the specialist software by CHI, RTIBuilder, comes into its own.

For each artifact, start a new project and then open a folder and transfer the JPEG files. The program identifies the target in the highlighted box, though often not perfectly, so manual adjustment ensures that the sphere is accurately delineated. The images are then blended to create a composite image of the target showing all the light sources in the one image. This is very useful to check that coverage has been sufficiently even (see Fig. 3c). After this point the images can be cropped, which can include the removal of the targets from the image. What is in this cropped image will constitute the composition of the final product.

Once the processing is complete, it is possible to initiate the polynomial texture mapping (PTM) using the separate PTM Fitter program, which is also downloaded from $\mathrm{CHI}$ and on the first application only needs to be mapped from the RTIBuilder program. The resulting PTM output can be formatted for color and size, and then named. As with all digital images, ensure a consistent and intelligible naming system. It is now necessary to execute the fitting process, and once 
completed the resulting PTM file will be stored in the "finished_files" folder. In most cases each set of images will be processed once to create one PTM file, but it is possible to alter variables and run the process again.

Composite images that have slightly different qualities from the PTM can be created by using the Hemispheric Harmonics (HSH) option- "Highlight Based (HSH Fitter)" - produced jointly by the University of California Santa Cruz and CHI. This generates not PTM but RTI-HSH files, though at present with fewer options in rendering and viewing modes. The relative strengths of each type for historical archaeology are discussed below, but creating both types of output file only adds a small amount of time to the processing as most stages are completed and then the final fitting stage can be repeated with each option creating a pair of PTM and RTI-HSH files for the same artifact.

A more detailed step-by-step account of the processing stages can be found in Duffy (2013:10-12), so these are not repeated here, but be sure to check any updates from $\mathrm{CHI}$ as the software is periodically upgraded and the details of this work flow may change.

\section{Viewing RTI Images}

The viewing of the images requires different software. PTM and RTI-HSH files can be viewed using RTIViewer, another item of freeware available for download from CHI. Anyone interactively viewing the PTM or RTI-HSH files requires this software, but they do not need RTIBuilder, nor do they need to understand any of the processing stages that have generated these files. It is thus possible to make these files widely available and accessible, and they are easily emailed as they tend to be $1-2 \mathrm{MB}$ in size. Basic operating of RTIViewer is extremely easy. It is possible to alter many variables to enhance images for particular purposes, but this is not necessary for many casual users.

Once a file has been opened, the direction of the light source can be easily adjusted by using the mouse to move the white dot about on the green sphere in the top right of the screen (Fig. 4). It is also possible to zoom in and out of the image to study fine detail using either the mouse or adjusting the number in the zoom window to the right of the green sphere. The real strength of the software is that various rendering options can create very different images, each with their own strengths (Figs. 5, 6, 7, 8, 9 and 10). Images load as Defaults, but clicking on the downward arrow produces a menu of options. At present with RTI-HSH files there are only Specular Enhancement and Normals Visualization, but with PTM files there is a much greater range of options; several have proved valuable to the authors, and others may find different options worthwhile. The different options take little time to generate, so it is easy to experiment with any one artifact. Any image can be saved as a JPEG using the camera icon. Of all the options, Specular Enhancement and Normals Visualization have proven particularly effective and create images clearly different from standard photography; these deserve particular discussion.

\section{Specular Enhancement}

This rendering generates a largely monochrome image that can have a shiny, wet look. Changes in direction of light can be simulated by the mouse-operated, green rollerball. For some objects the light source is best just off vertical, for others the most impressive results come from very oblique angles. For artifacts with finely incised designs, careful adjustment can reveal details that are otherwise hard to capture. If a drawn image is required, a series of images can be saved and then used as a base for a drawn composite. In some cases it is possible to identify the sequence of incisions, which may inform either manufacturing techniques or uses of the artifact. Both PTM and RTI-HSH files can generate Specular Enhancement images, but the PTM files generate more glossy images, with the RTI-HSH files producing more granular images that, for most purposes within historical archaeology, are less useful (compare Figs. 5c, 7c, 10c against Figs. 5d, 7d, 10d).

\section{Normals Visualization}

The image generated by this rendering technique is a noninteractive composite image representing the 3-D surface of the object. It has a largely violet hue, though it can have highlights in yellow and green. As it is a composite, there is only one image, but PTM files tend to produce greater amounts of highlight, which can be visually distracting, and we have found that RTI-HSH files are more appropriate for historical archaeology subjects when a Normals Visualization image is required (compare particularly Figs. 5e, 10e against Figs. 5f, 10f). Once saved using the camera icon, standard photograph processing software can be used to convert 


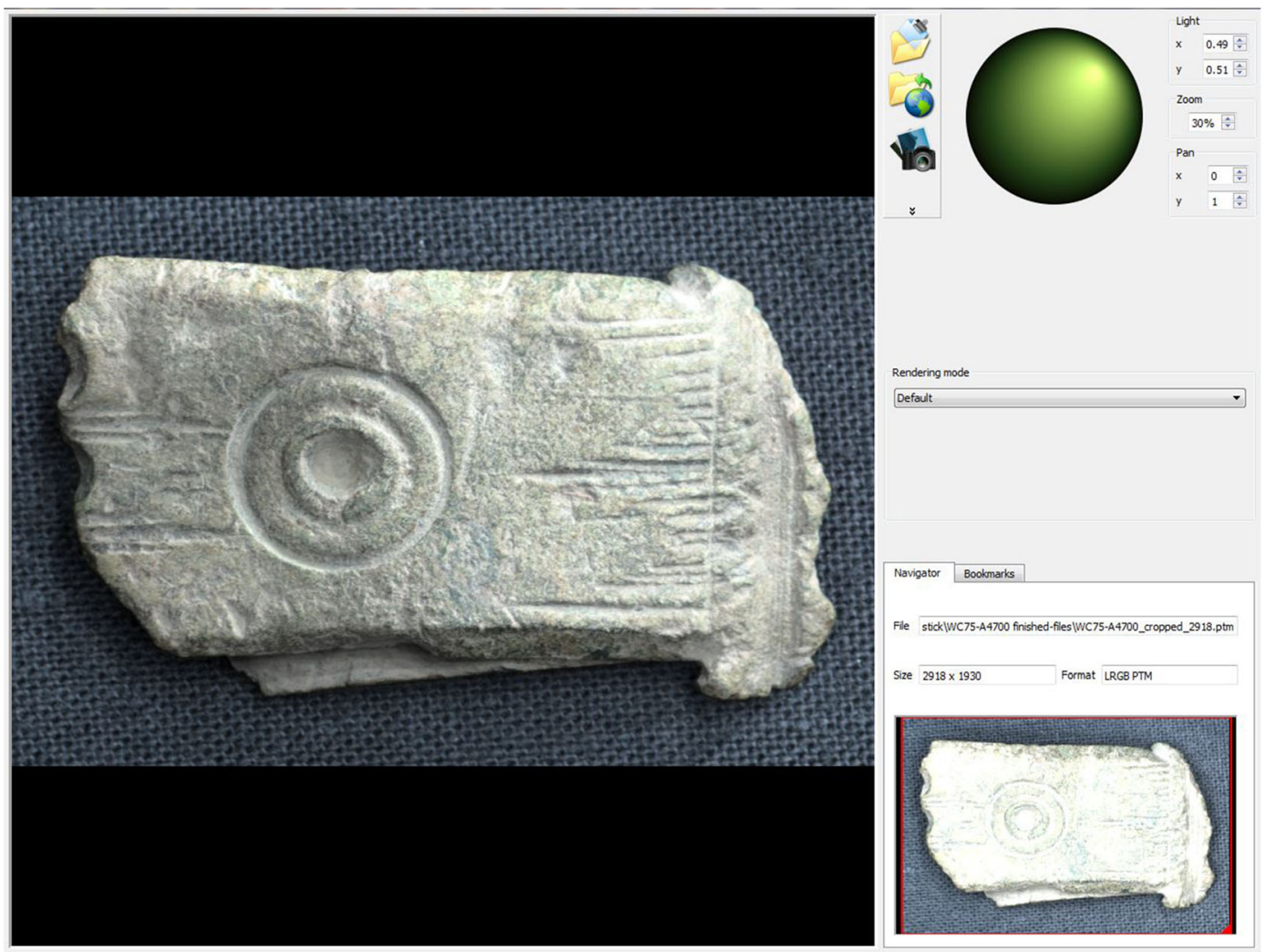

Fig. 4 RTIViewer screen with green sphere (top right) to adjust direction of light. Below this the Rendering mode is set at Default but can be opened to reveal the options, depending on whether a PTM or RTI-HSH file is uploaded. (Image by Harold Mytum, 2017).

the Normals Visualization image into a standard monochrome product; in some cases, a slight sharpening enhances the contrast for publication (Fig. 8d, 8f).

\section{Examples of RTI Use in Historical Archaeology}

These examples indicate the effects of using the different options on a range of artifacts and materials.

\section{Clay Pipes}

The method can create excellent images of pipe stamps, and adjusting light direction can reveal details hard to see otherwise (Figs. 5, 6). Single images that use all the data can be created with the Normals Visualization (Figs. 5e, 5f, 6d) and Static Multi Light options (Fig. $5 \mathrm{~h})$. With white pipe clay, images can in effect be monochrome, but use and staining can be visible, and for the curved surface of a pipe bowl the Coefficient Unsharp Masking and Diffuse Gain options can be effective (Fig. 6a, 6b). The Specular Enhancement and
Normals Visualization images may also have some use (Fig. 6c, 6d).

\section{Copper Alloy}

Details of decoration can be easily identified and recorded for copper alloy artifacts (Figs. 4, 7), and some types of image are particularly informative regarding surface texture and condition, such as Luminance Unsharp Masking (Fig. 7h). Specular Enhancement with PTM files (Fig. 7c) is usually superior to the images produced from RTI-HSH files (Fig. 7d). RTI imagery has been successfully applied to coins (Mudge et al. 2005) and incised artifacts (Bevan et al. 2013).

\section{Bone and Antler}

Artifacts can be photographed to reveal form and decoration, but also details of construction (Newman 2015) and use with abrasions on surfaces (Fig. 8). Slight scratches can be particularly visible with Specular 
Fig. 5 Clay pipe stamp: (a)

Default PTM; (b) Default RTI-

HSH; (c) Specular Enhancement PTM; (d) Specular Enhancement RTI-HSH; (e) Normals

Vizualization PTM; $(f)$ Normals RTI-HSH; $(g)$ Dynamic Multi Light PTM; (h) Static Multi Light PTM. (Images by authors, 2017).
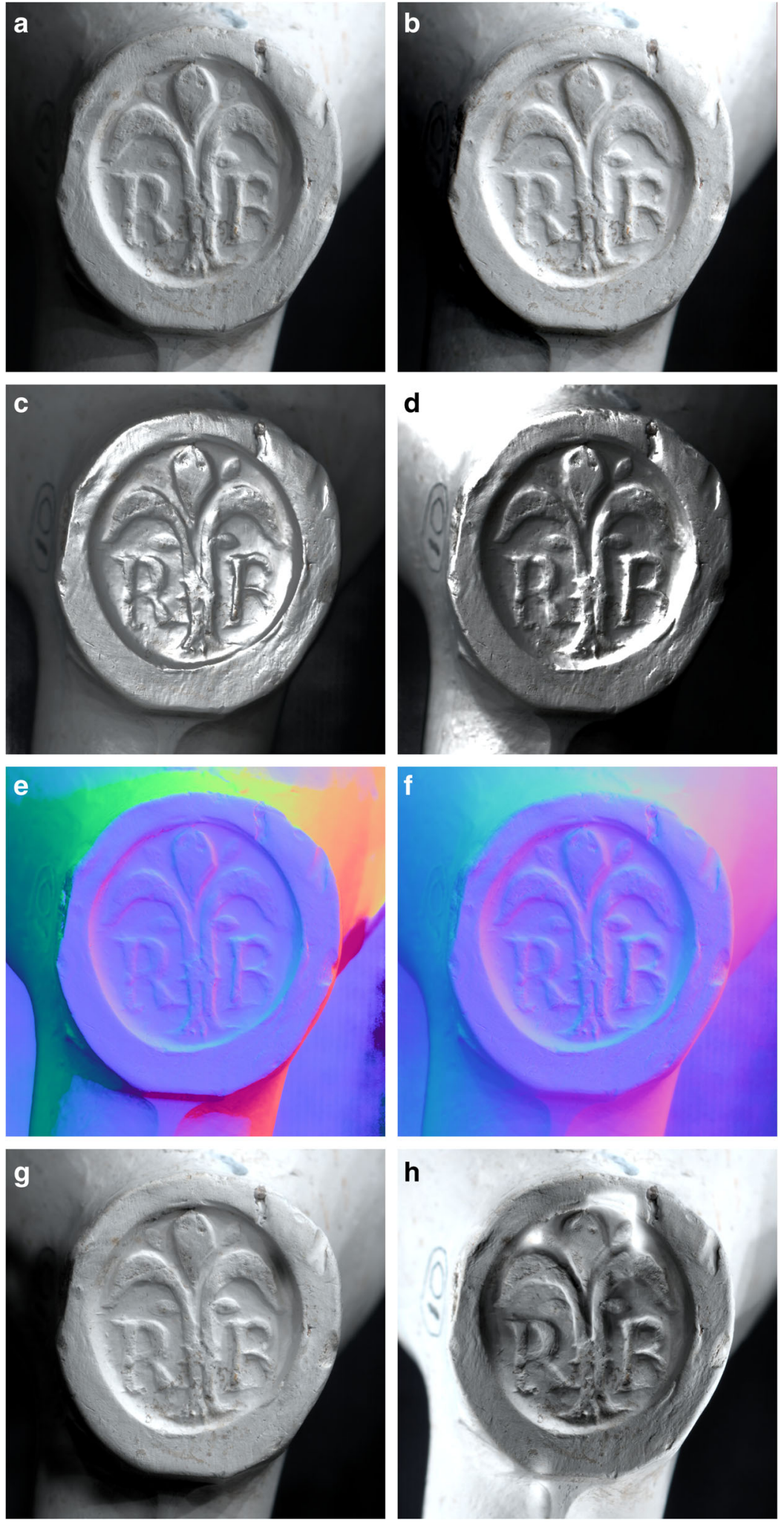

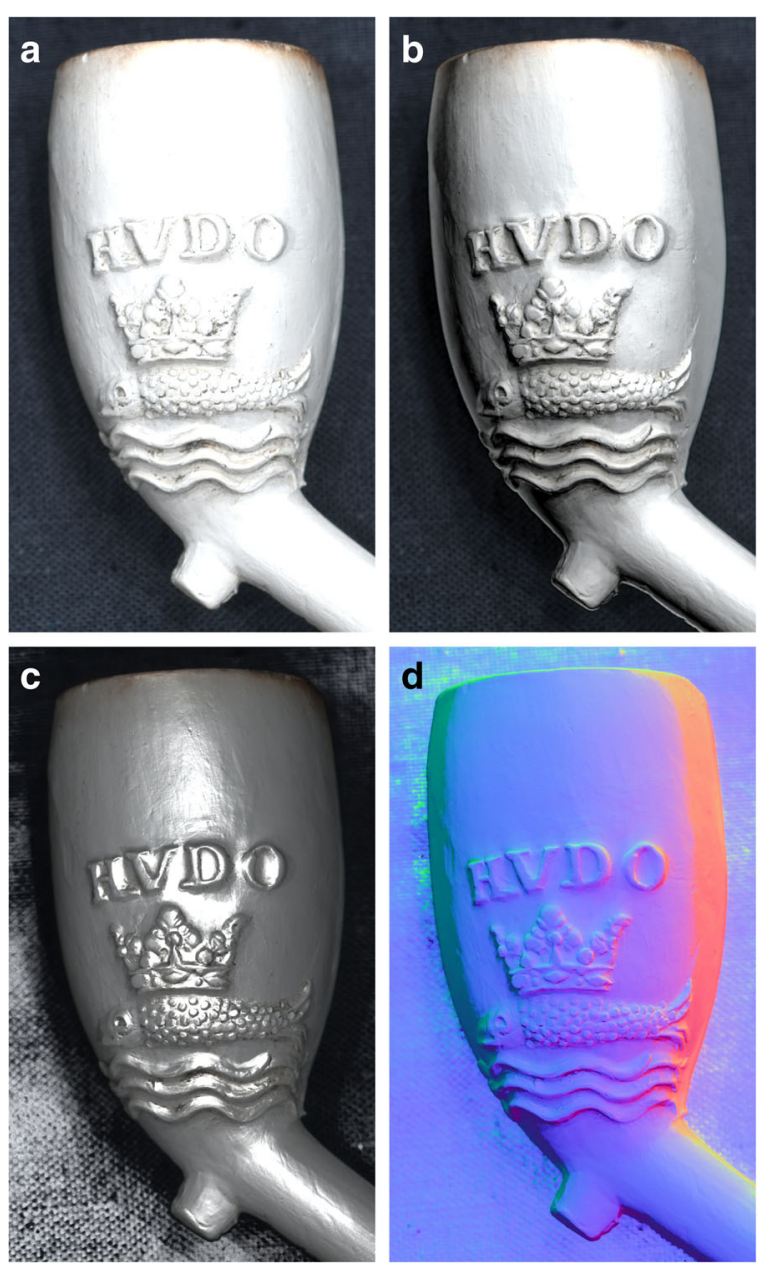

Fig. 6 Clay pipe bowl: (a) Coefficient Unsharp Masking PTM; (b) Diffuse Gain PTM; (c) Specular Enhancement PTM; (d) Normals Visualization PTM. (Images by authors, 2017).

Enhancement (Fig. 8c). Butchery marks can also be identified and illustrated using RTI.

\section{Glass}

This material can be difficult to photograph, especially if transparent, but some items work well with this method. The Diffuse Gain option can provide effective images without highlighting (Fig. 9a), and Specular Enhancement can provide clear evidence of details such as the bubbles in the glass (Fig. 9b).

\section{Stone}

The application of RTI has proved highly successful for gravestone recording (Mytum et al. 2017; Mytum 2018) and for graffiti (Cosentino et al. 2015). Varying the light angle in RTIViewer can allow the reading of text not intelligible in the field. It can also be particularly effective in identifying very fine lines such as lightly scratched graffiti and setting out lines on inscriptions, and some of the images reduce the impact of variation in color and presence of lichens on monuments (Fig. 10).

\section{Fieldwork Hints Derived from the Authors' Experience}

It is important to set the equipment up so that it is easy to move the light to all the various locations, even if this makes positioning of the artifact beneath the camera more difficult. This is only done once for each set of photographs, but there are many flash positions and it is important that this can be conveniently achieved in a systematic order. Keep spectators well away from all the equipment once set up, and have no movement within the field of view even between images, if at all possible.

Even with filters, very bright sunlight can be problematic in that the flash does not make a sufficient impact. Indoors, draw blinds and turn off any lights. Outside, it may be necessary to work early morning or evening, or even at night. However, working on sunny days in British and Irish summers has still produced good gravestone images. It may be possible to create a screen to cast a shadow on the in situ artifact to increase the impact of the flash, as long as the screen is not in the way for any of the flash positions; in some situations an umbrella will work well.

Avoid shadows cast by tripod legs, the target spheres, assistants, and - for in situ items - vegetation or structures. These, and excavation trench walls, can make $\mathrm{H}$ RTI impossible, but if only a few of the potential photographs are affected, it is likely that good results can still be achieved as long as light is from enough different directions. Although 45-60 images are often taken for $\mathrm{H}-\mathrm{RTI}$, it is possible to create a useful composite from as few as 24 images, as long as these are reasonably well spread. You can see how effective your spread is with the blended image created during the processing (see Fig. 3c).

Establish a clear routine in the order of positioning the flash so that it is easy to know what positions have been used, and which have still to be taken, and thus ensure even coverage. Make sure that as the flash is moved from one position to another it is consistently 
Fig. 7 Copper alloy mount: $(a)$ Default PTM; (b) Default RTIHSH; (c) Specular Enhancement PTM; (d) Specular Enhancement RTI-HSH; (e) Normals

Visualization PTM; $(f)$ Normals Visualization RTI-HSH; $(g)$ Dynamic Multi Light PTM; $(h)$ Luminance Unsharp Masking PTM. (Images by authors, 2017).
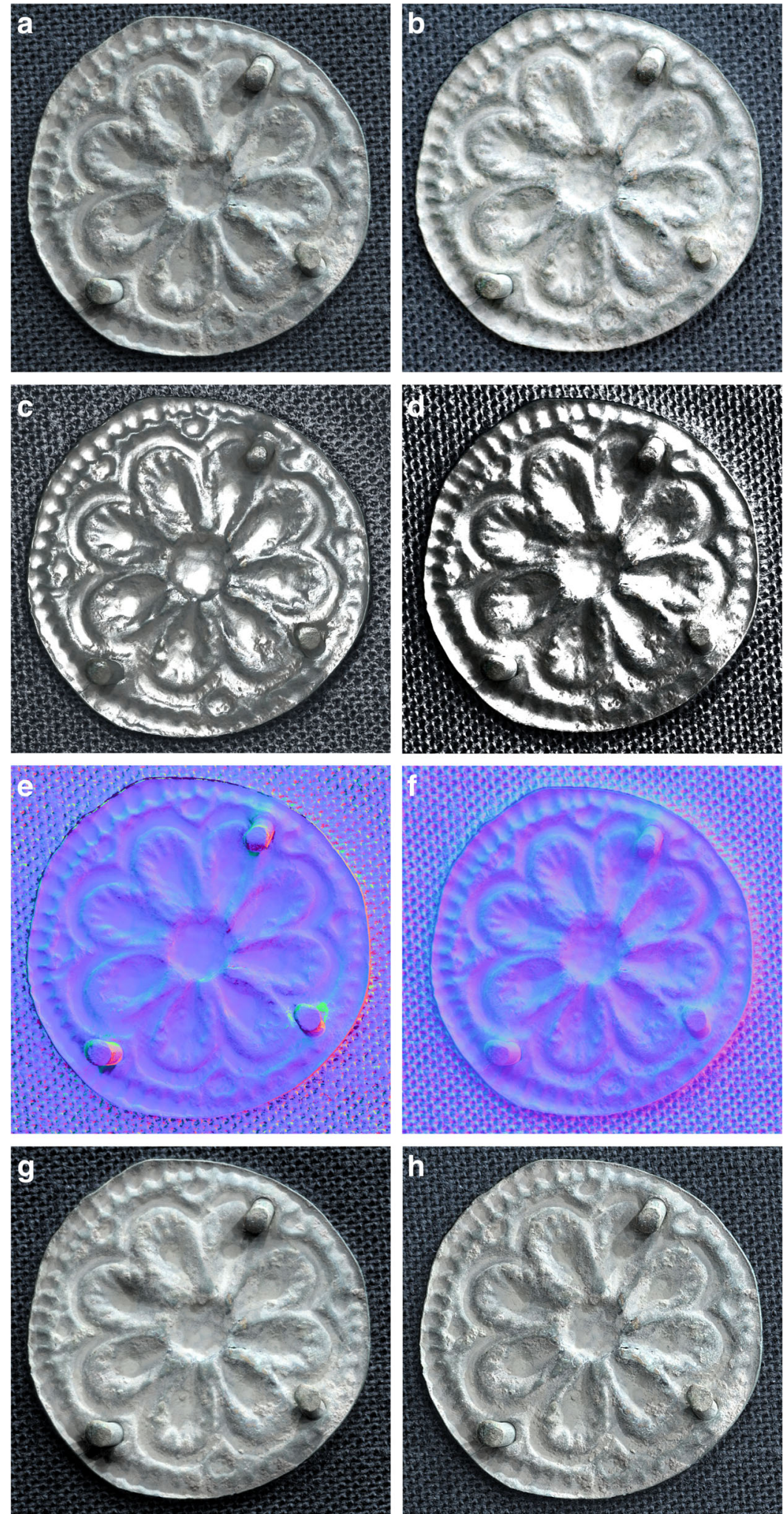
Fig. 8 Bone die: (a) Default PTM; (b) Diffuse Gain PTM; (c) Specular Enhancement PTM; (d) Normals Visualization RTI-HSH; (e) Static Multi Light PTM; (f) Normals Visualization RTI-HSH monochrome and sharpened with photographic processing software. (Images by authors, 2017).
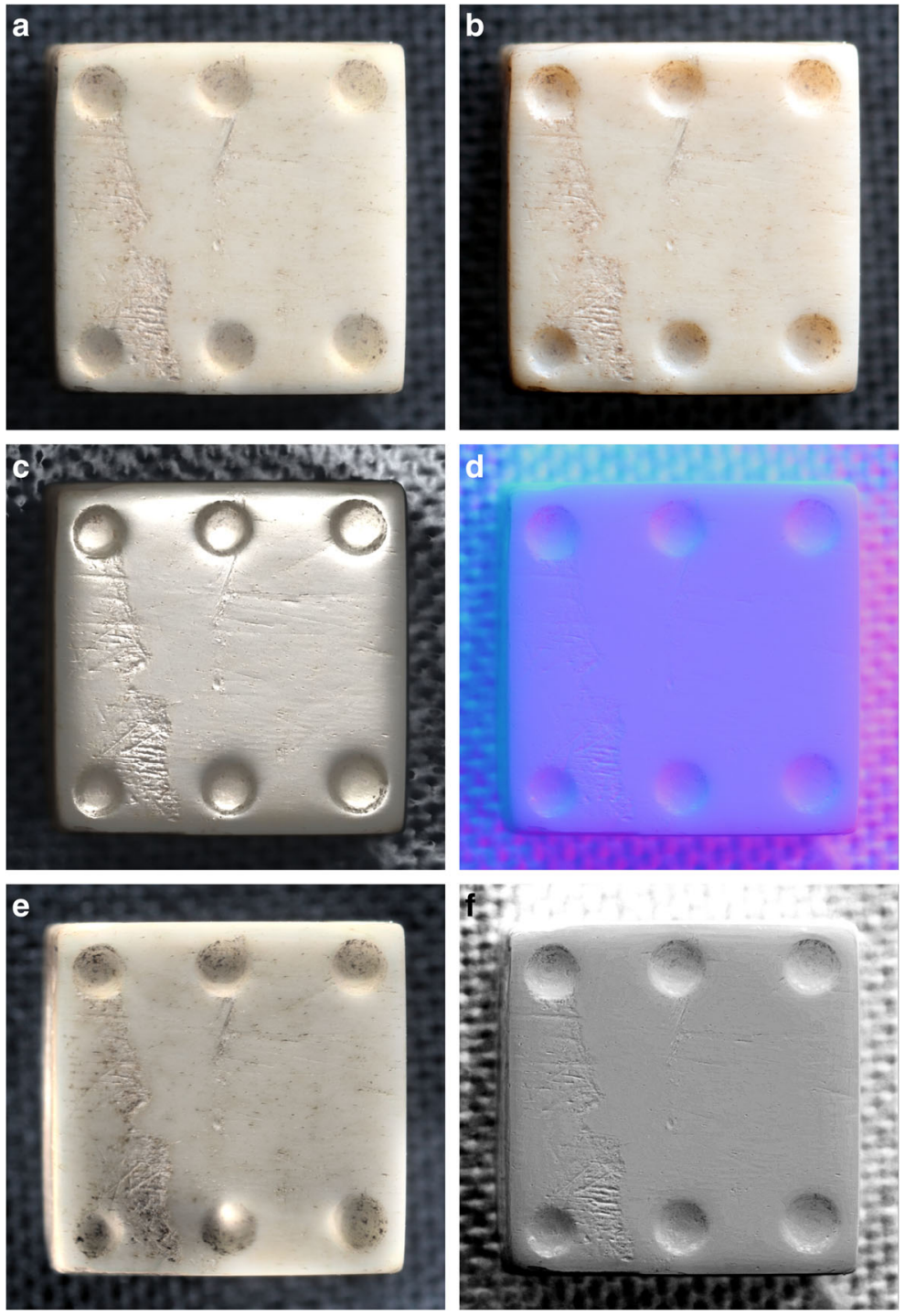

Fig. 9 Glass bottle base: (a) Diffuse Gain PTM; (b) Specular Enhancement PTM. (Images by authors, 2017).
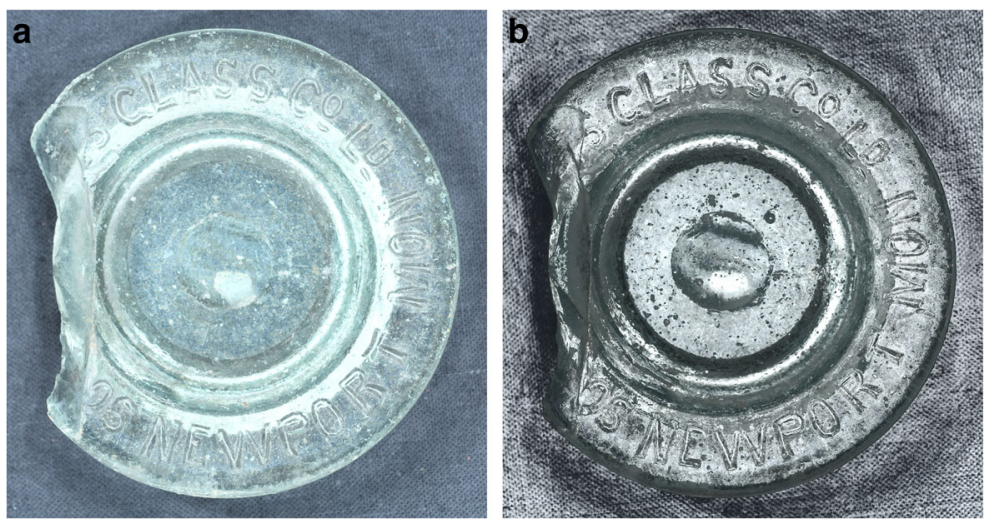

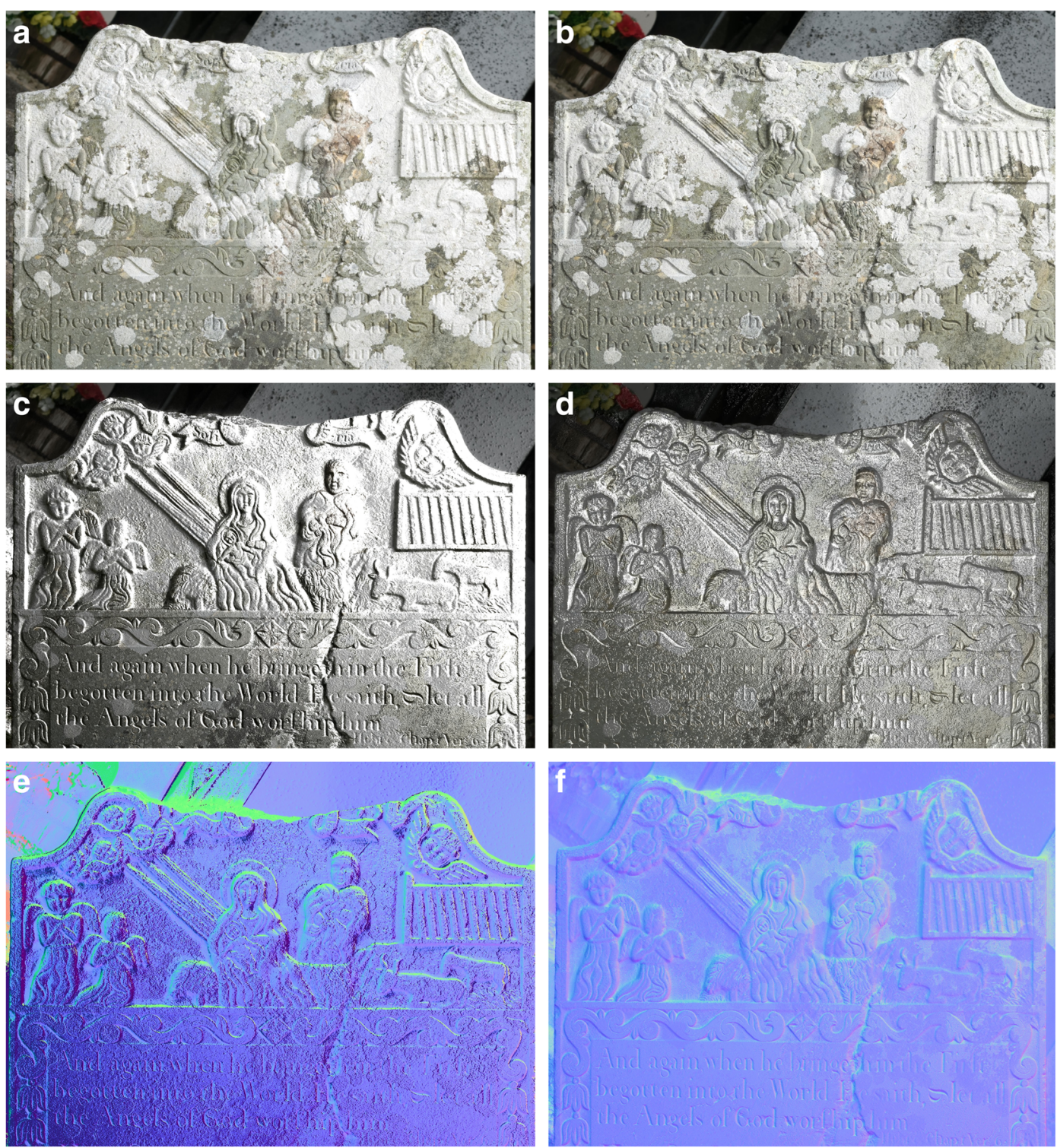

Fig. 10 Gravestone: (a) Default PTM; (b) Default RTI-HSH; (c) Specular Enhancement PTM; (d) Specular Enhancement RTI-HSH; (e) Normals Visualization PTM; $(f)$ Normals Visualization RTI-HSH. (Images by authors, 2017).

facing the artifact; it is easy to move but not adjust the orientation of the flash. If there is a problem with one image (e.g., shadow or training cable), just make a note to edit out that image later, and proceed. Only abandon the set of images if the camera has moved.

An electronic distance meter with an audible signal, affixed to the flash, can provide an integrated unit for positioning the light source at a uniform distance from the artifact. Then, the only concern is the position and orientation of the light source. However, we have often used "low-tech" adaptations, such as a stick or piece of string of the appropriate length, as well as a hand tape set at the appropriate distance. With electronic distance meter and remote camera and flash operation, it is possible to conduct RTI with one person, but it is normal to have a team of two.

Ensure that all the equipment has sufficient power for the amount of recording. Have available spare sets of batteries for camera and flash, and make sure that the laptop will last the required time in the field. When you come to create folders and file names, use a logical naming system and record this carefully in the field notes. 


\section{Data Archiving}

The RTISAD project has collaborated with the Archaeology Data Service in the United Kingdom to create an RTI repository, together with a costing model for deposition.

\section{Conclusion}

RTI (including H-RTI) can be highly effective in recording artifacts, and is particularly effective for identifying surface features such as those indicating production methods, use, and postdepositional taphonomy. The research and practice reported here demonstrate that it is effective across a wide range of materials but has, as yet, been underused in historical archaeology. H-RTI can be carried out in the field (terrestrial or underwater) or lab, with little equipment beyond that required for standard photography, and all the necessary software is freeware. The final images can be easily distributed. The method deserves wider appreciation and application within the discipline.

Open Access This article is distributed under the terms of the Creative Commons Attribution 4.0 International License (http:// creativecommons.org/licenses/by/4.0/), which permits unrestricted use, distribution, and reproduction in any medium, provided you give appropriate credit to the original author(s) and the source, provide a link to the Creative Commons license, and indicate if changes were made.

\section{References}

Bevan, George, Daryn Lehous, and Richard Talbert

2013 Reflectance Transformation Imaging of a "Byzantine" Portable Sundial. Zeitschrift für Papyrologie und Epigraphik 187:221-229.

Cosentino, Antonino, Samantha Stout, and Carmelo Scandurra

2015 Innovative Imaging Techniques for Examination and Documentation of Mural Paintings and Historical Graffiti in the Catacombs of San Giovanni, Syracuse. International Journal of Conservation Science 6(1):23-34.

Cultural Heritage Imaging (CHI)

2013 Reflectance Transformation Imaging. Guide to RTIViewer. Version 1.1. Cultural Heritage Imaging and Visual Computing Lab, ISTI-Italian National Research Council, San Francisco, CA $<$ http://CulturalHeritageImaging.org/downloads/>. Accessed 27 July 2017.
Cultural Heritage Imaging (CHI)

2014 Reflectance Transformation Imaging Glossary of Photographic and Technical Terms for RTI. Version 1. Cultural Heritage Imaging, San Francisco, CA $<\mathrm{http}$ //CulturalHeritageImaging.org/downloads/>. Accessed 27 July 2017.

Cultural Heritage Imaging (CHI)

2018 Culture Heritage Imaging: A Nonprofit Corporation, Helping Humanity Save History. About Us. Website $<$ http://culturalheritageimaging.org/About_Us/>. Accessed 1 April 2018.

Duffy, Sarah M.

2013 Multi-Light Imaging for Heritage Applications. English Heritage, London, UK < https://www .historicengland.org.uk/images-books /publications/multi-light-imaging-heritage -applications/>. Accessed 27 July 2017.

Earl, Graeme, Gareth Beale, Kirk Martinez, and Hembo Pagi

2010 Polynomial Texture Mapping and Related Imaging Technologies for the Recording, Analysis and Presentation of Archaeological Materials. The International Archives of the Photogrammetry, Remote Sensing and Spatial Information Sciences 38(5):218-223.

Gabov, Alexander, and George Bevan

2011 Recording the Weathering of Outdoor Stone Monuments Using Reflectance Transformation Imaging (RTI): The Case of the Guild of All Arts (Scarborough, Ontario). Journal of the Canadian Association for Conservation 36:3-14.

Malzbender, Tom, Dan Gelb, and Hand Wolters

2001 Polynomial Texture Maps. In SIGGRAPH '01: Proceedings of the 28th Annual Conference on Computer Graphics and Interactive Techniques, pp. 519-552. ACM, New York, NY.

Means, Bernard K., Ashley McCuistion, and Courtney Bowles

2013 Virtual Artifact Curation of the Historical Past and the NextEngine Desktop 3D Scanner. Technical Briefs in Historical Archaeology 7:1-12.

Mudge, Mark, Jean-Pierre Voutaz, Carla Schroer, and Martin Lum 2005 Reflection Transformation Imaging and Virtual Representations of Coins from the Hospice of the Grand St. Bernard. In VAST 2005: 6th International Symposium on Virtual Reality, Archaeology and Intelligent Cultural Heritage, Mark Mudge, Nick S. Ryan, and Roberto Scopigno, editors, pp. 29-40. Eurographics Association, Geneva, Switzerland.

Mytum, Harold

2018 Nativity Scenes on Gravestones in County Louth, Ireland (forthcoming). Church Monuments 32.

Mytum, Harold, with Kate Chapman, J. R. Peterson, and Alistair Cross 2017 Reflectance Transformation Imaging (RTI): Capturing Gravestone Detail via Multiple Digital Images. Association for Gravestone Studies Newsletter 41(2): $3-10$.

Newman, Sarah E.

2015 Applications of Reflectance Transformation Imaging (RTI) to the Study of Bone Surface Modifications. Journal of Archaeological Science 53:536-549. 
Padfield, Joseph, David Saunders, and Tom Malzbender

2005 Polynomial Texture Mapping: A New Tool for Examining the Surface of Paintings. ICOM Committee for Conservation 1:504-510.

Pawlowicz, Leszek

2015 Creating a Portable Dome-RTI System for Imaging Lithics <https://culturalheritageimaging.wordpress .com/2015/05/26/creating-a-portable-dome-rti -system-for-imaging-lithics/>. Accessed 27 July 2017.

Piquette, Kathryn E.

2011 Reflectance Transformation Imaging (RTI) and Ancient Egyptian Material Culture. Damqatum-The CEHAO Newsletter $7<\mathrm{http} / / /$ bibliotecadigital.uca .edu.ar/repositorio/revistas/damqatum7-eng.pdf>. Accessed 8 April 2018.

Rivera, Patrick S.

2014 Applying the Methods of Evidence Photography to Archaeological Collections. Technical Briefs in Historical Archaeology 8:22-31.
Selden, Robert Z.

2015 Using Photogrammetry to Document, Analyze, and Reverse-Engineer Grave Markers. Technical Briefs in Historical Archaeology 9:49-56.

Selmo, David, Fraser Sturt, James Miles, Philip Basford, Tom Malzbender, Kirk Martinez, Charlie Thompson, Graeme Earl, and George Bevan.

2017 Underwater Reflectance Transformation Imaging: A Technology for In Situ Underwater Cultural Heritage Object-Level Recording. Journal of Electronic Imaging 26(1), 011029. https://doi.org/10.1117/1 JEI.26.1.011029. Accessed 1 April 2018. 